Article

\title{
Numerical Evaluation of the Use of Aluminum Particles for Enhancing Solid Rocket Motor Combustion Stability
}

\section{David Greatrix}

Department of Aerospace Engineering, Ryerson University, 350 Victoria Street, Toronto, ON M5B 2K3, Canada; E-Mail: greatrix @ ryerson.ca; Tel.: +1-416-979-5000 (ext. 6432); Fax: +1-416-979-5056

Academic Editor: Vasily Novozhilov

Received: 24 November 2014 / Accepted: 27 January 2015 / Published: 3 February 2015

\begin{abstract}
The ability to predict the expected internal behaviour of a given solid-propellant rocket motor under transient conditions is important. Research towards predicting and quantifying undesirable transient axial combustion instability symptoms typically necessitates a comprehensive numerical model for internal ballistic simulation under dynamic flow and combustion conditions. On the mitigation side, one in practice sees the use of inert or reactive particles for the suppression of pressure wave development in the motor chamber flow. With the focus of the present study placed on reactive particles, a numerical internal ballistic model incorporating relevant elements, such as a transient, frequency-dependent combustion response to axial pressure wave activity above the burning propellant surface, is applied to the investigation of using aluminum particles within the central internal flow (particles whose surfaces nominally regress with time, as a function of current particle size, as they move downstream) as a means of suppressing instability-related symptoms in a cylindrical-grain motor. The results of this investigation reveal that the loading percentage and starting size of the aluminum particles have a significant influence on reducing the resulting transient pressure wave magnitude.
\end{abstract}

Keywords: combustion instability; solid rocket motor; aluminum particles

\section{Introduction}

With respect to the internal ballistics of solid-propellant rocket motors (SRMs), one ideally should be able to anticipate the behaviour of a given motor under transient conditions. Over the last number of decades, there has been a number of research efforts directed towards a better understanding of the 
physical mechanisms, or at least the surrounding factors, behind the appearance of transient symptoms associated with nonlinear axial combustion instability in SRMs [1,2]. The primary symptom for traditional nonlinear axial combustion instability is a sustained cyclic axial pressure wave presence of significant amplitude in the combustion chamber of the motor. A second symptom is the occasional appearance of a base pressure rise in the combustion chamber that accompanies the axial or transverse pressure wave motion that is present, referred to as a dc shift. From an SRM design viewpoint, there is considerable motivation to better determine how one might more precisely suppress, if not eliminate, these symptoms.

It has long been known that inert (non-reactive) or reactive particles in the internal core flow can help to suppress axial combustion instability symptoms [3-5]. It is not always clear as to the quantity of particle loading (and corresponding particle size) that is needed to adequately suppress the given symptoms, if that is the suppression technique being exploited [1]. Additionally, it is not always clear that the effectiveness of particle or additive loading is due entirely to particle/drag effects within the central core flow or, in fact, in part or in whole due to an altered combustion response or sensitivity (e.g., to normal acceleration) of the propellant, as a result of the presence of the particle/additive at or near the burning surface (before entering the core flow region) [6].

In the present investigation, an updated numerical model developed from previous SRM studies [7-11] is used in the prediction of the unsteady instability-related behaviour in a reference small cylindrical-grain motor. In conjunction, the internal ballistic simulation model will allow for an evaluation of the corresponding effectiveness of placing reactive spherical aluminum particles in the central chamber flow as a means of suppressing instability symptoms. The transient burning response of the solid propellant is a primary mechanism for sustaining appreciable travelling pressure waves in the combustion chamber and will of course be accounted for in this internal ballistic simulation study. In addition, the effect of normal acceleration (through radial vibration of the motor structure) on the propellant burning process will be accounted for in the production of some of the example results displayed later in this paper.

\section{Numerical Model}

In the present investigation, the SRM is assumed to be positioned on a static test stand, as schematically represented in Figure 1. In this case, the cylindrical-grain motor is free to vibrate radially without any external constraint (i.e., only constrained in some cases by the thick steel static test sleeve surrounding the aluminum flight weight motor casing), while axial motion is constrained to a large degree by the thrust-measuring load cell (represented in the predictive model as a spring/damper system) at the left-hand boundary of the motor's head end. Under normal (nominal) quasi-equilibrium operating conditions, the internal gas-particle flow moves smoothly from the burning propellant surface into the axial flow, from left-to-right, as per Figure 1, through and beyond the exhaust nozzle. 


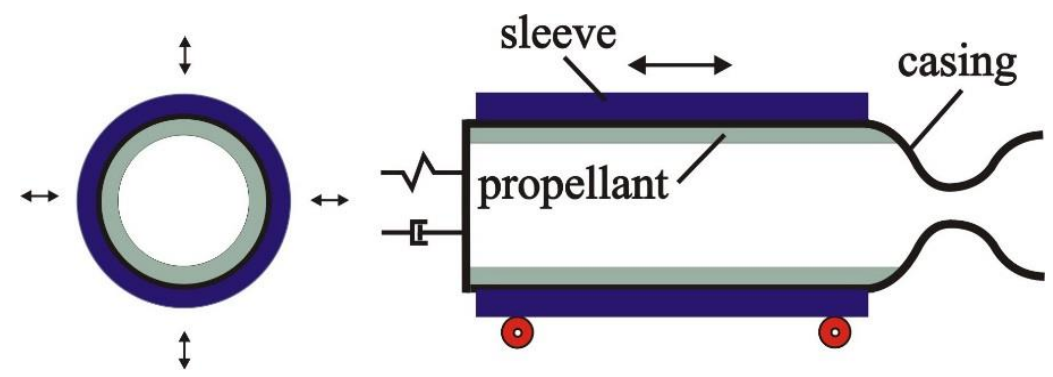

Figure 1. The reference solid-propellant rocket motor (SRM) model setup, for static test firing in the laboratory.

The equations of motion describing the non-steady core flow within the SRM must be solved in conjunction with the local surface regression rate $r_{\mathrm{b}}$ of the solid propellant and the surrounding structure's instantaneous geometric deformation. As pertains to the present study of a motor having a larger length-to-diameter ratio, the quasi-one-dimensional hydrodynamic conservation equations for the axial gas flow are given below:

$$
\begin{gathered}
\frac{\partial \rho}{\partial t}+\frac{\partial(\rho u)}{\partial x}=-\frac{1}{A} \frac{\partial A}{\partial x} \rho u+\left(1-\alpha_{\mathrm{p}}\right) \rho_{\mathrm{s}} \frac{4 r_{\mathrm{b}}}{d}-\left(\frac{4 r_{\mathrm{b}}}{d}+\kappa\right) \rho+\sum_{i=1}^{N_{s e t}} \rho_{\mathrm{m}} r_{\mathrm{b}, \mathrm{pi}} \frac{\rho_{\mathrm{pi}}}{m_{\mathrm{pi}}} \pi \cdot d_{\mathrm{mi}}^{2} \\
\frac{\partial(\rho u)}{\partial t}+\frac{\partial}{\partial x}\left(\rho^{2}+p u^{2}\right)=-\frac{1}{A} \frac{\partial A}{\partial x} \rho u^{2}-\left(\frac{4 r_{\mathrm{b}}}{d}+\kappa\right) \rho u-\rho a_{\ell}-\sum_{i=1}^{N_{\mathrm{se}}} \frac{\rho_{\mathrm{pi}}}{m_{\mathrm{pi}}} D_{i} \\
\frac{\partial(\rho E)}{\partial t}+\frac{\partial}{\partial x}(\rho u E+u p)=-\frac{1}{A} \frac{\partial A}{\partial x}(\rho u E+u p)-\left(\frac{4 r_{\mathrm{b}}}{d}+\kappa\right) \rho E+\left(1-\alpha_{\mathrm{p}}\right) \rho_{\mathrm{s}} \frac{4 r_{\mathrm{b}}}{d}\left(C_{\mathrm{p}} T_{\mathrm{f}}+\frac{v_{\mathrm{f}}^{2}}{2}\right)
\end{gathered}
$$

The total specific energy of the gas is defined for an ideal gas as:

$$
E=\frac{p}{(\gamma-1) \rho}+\frac{u^{2}}{2}
$$

In Equation (1), for the conservation of mass, one can see the input of gas entering the central flow from the nominally spherical reactive particles, as specified by the final term on the right-hand side. With respect to the remaining (largest) mass input from the propellant burning surface, the loading fraction of solid particles in the propellant, $\alpha_{\mathrm{p}}$, influences the amount of propellant gas entering into the central flow, as per the second term on the right-hand side of Equation (1). In Equation (2), for conservation of axial momentum, one sees the drag force of the particles on the gas in the last term on the right-hand side. In Equation (3), for the conservation of energy, one sees the contribution of high-temperature particle gas heat energy in the final term on the right-hand, while one sees the drag and heat energy transfer between the particles and gas in the term next to it.

A one-dimensional (1D) approach, as described by the above conservation equations, will not capture all of the physical phenomena at play in a motor's interior flow (relative to what can potentially be obtained via a two-dimensional axisymmetric or three-dimensional flow model). However, for a motor with a larger length-to-diameter ratio, the 1D approach can capture at least some useful elements of the physical phenomena that are of interest for this study, as made evident later in this paper. In addition, one can note that a 1D numerical model has the nominal advantages of allowing for simpler modelling and quicker turnaround times for the computed results. 
Assuming that one starts with a single set of reactive particles of one nominal starting diameter within the solid propellant, one would, in turn, need to account for the diminishing size of those particles once they exit the solid propellant surface and begin moving downstream in the internal core flow. One can separate the collection of different-sized particles appearing in a given volumetric element into their applicable size subset or bracket, e.g., for a 10-m starting particle diameter, employ 10 size subsets ( $i=1$ to 10 subsets, for particles sized between 10 and $9 \mathrm{~m}$ for $i=1$, between 9 and $8 \mathrm{~m}$ for $i=2$, etc., down to a zero particle diameter). For greater accuracy, one would want to use more size subsets with smaller size ranges between them, the trade-off being an increased computational turnaround time. One will need to keep track of particles transitioning from a higher sized bracket into the adjacent lower size bracket as they burn down at their respective regression rate $r_{b, p i}$. For example, particles being added into an $i$-th bracket from its upper boundary with its adjacent higher size bracket (at $i-1)$ over a small computational time increment will adjust the particle density therein as follows:

$$
\left.\rho_{\mathrm{pi}}\right|_{\text {new }}=\left.\rho_{\mathrm{pi}}\right|_{\text {old }}+\left.\frac{r_{\mathrm{b}, \mathrm{p}, i-1} \Delta t}{\Delta r_{\text {bracket }}} \cdot \rho_{\mathrm{p}, i-1}\right|_{\text {old }}
$$

where $\Delta r_{\text {bracket }}$ is the $i$-th bracket distance in terms of particle radius ( $0.5 \mathrm{~m}$ for the above example). Similarly, particles being lost from an $i$-th bracket through its lower boundary with its adjacent lower size bracket (at $i+1$ ) will adjust the particle density in the $i$-th bracket as follows:

$$
\left.\rho_{\mathrm{pi}}\right|_{\text {new }}=\left.\rho_{\mathrm{pi}}\right|_{\text {old }}-\left.\frac{r_{\mathrm{b}, \mathrm{pi}} \Delta t}{\Delta r_{\text {bracket }}} \cdot \rho_{\mathrm{p}, i}\right|_{\text {old }}
$$

For the simulation runs done in this study, the size brackets are initially empty and allowed to fill up to their quasi-equilibrium value with a sufficient period of time allotted. The number of particles in a given bracket at a given axial location (flow element of volume $\forall$ ) can be established via:

$$
N_{i}=\frac{\rho_{\mathrm{pi}} \forall}{m_{\mathrm{pi}}}
$$

where the mass of an individual particle is ascertained via:

$$
m_{\mathrm{pi}}=\frac{\pi}{6} \cdot d_{\mathrm{mi}}^{3} \rho_{\mathrm{m}}
$$

The corresponding equations of motion for an $i$-th particle set within the axial flow may be described by the following:

$$
\begin{aligned}
& \frac{\partial \rho_{\mathrm{pi}}}{\partial t}+\frac{\partial\left(\rho_{\mathrm{pi}} u_{\mathrm{pi}}\right)}{\partial x}=-\frac{1}{A} \frac{\partial A}{\partial x} \rho_{\mathrm{pi}} u_{\mathrm{pi}}+\left.\alpha_{\mathrm{p}} \rho_{\mathrm{s}} \frac{4 r_{\mathrm{b}}}{d}\right|_{\text {for } i=1 \text { only }}-\left(\frac{4 r_{\mathrm{b}}}{d}+\kappa\right) \rho_{\mathrm{pi}} \\
& \frac{\partial\left(\rho_{\mathrm{pi}} u_{\mathrm{pi}}\right)}{\partial t}+\frac{\partial\left(\rho_{\mathrm{pi}} u_{\mathrm{pi}}{ }^{2}\right)}{\partial x}=-\frac{1}{A} \frac{\partial A}{\partial x} \rho_{\mathrm{pi}} u_{\mathrm{pi}}{ }^{2}-\left(\frac{4 r_{\mathrm{b}}}{d}+\kappa\right) \rho_{\mathrm{pi}} u_{\mathrm{pi}}-\rho_{\mathrm{pi}} a_{\ell}+\frac{\rho_{\mathrm{pi}}}{m_{\mathrm{pi}}} D_{i}
\end{aligned}
$$




$$
\begin{aligned}
\frac{\partial\left(\rho_{\mathrm{pi}} E_{\mathrm{pi}}\right)}{\partial t}+ & \frac{\partial\left(\rho_{\mathrm{pi}} u_{\mathrm{pi}} E_{\mathrm{pi}}\right)}{\partial x}=-\frac{1}{A} \frac{\partial A}{\partial x}\left(\rho_{\mathrm{pi}} u_{\mathrm{pi}} E_{\mathrm{pi}}\right)-\left(\frac{4 r_{\mathrm{b}}}{d}+\kappa\right) \rho_{\mathrm{pi}} E_{\mathrm{pi}}-\rho_{\mathrm{pi}} u_{\mathrm{pi}} a_{\ell} \\
& +\left.\alpha_{\mathrm{p}} \rho_{\mathrm{s}} \frac{4 r_{\mathrm{b}}}{d}\left(C_{\mathrm{m}} T_{\mathrm{f}}+\frac{v_{\mathrm{f}}^{2}}{2}\right)\right|_{\text {for } \mathrm{i}=1 \text { only }}+\frac{\rho_{\mathrm{pi}}}{m_{\mathrm{pi}}}\left(u_{\mathrm{pi}} D_{i}+Q_{i}\right)
\end{aligned}
$$

The total specific energy of a local grouping of particles from an $i$-th set is given by:

$$
E_{\mathrm{pi}}=C_{\mathrm{m}} T_{\mathrm{pi}}+\frac{u_{\mathrm{pi}}^{2}}{2}
$$

where $T_{\mathrm{pi}}$ is the mean temperature of that group of particles. As noted in the pertinent conservation equations, terms associated with particle mass or particle energy input from the propellant surface are only applicable when $i=1$. The one-dimensional conservation equations above essentially prescribe the movement of a collection of particles of comparable size (for the $i$-th set in question; in the sense as a quasi-continuous medium, but without exertion of any pressure of one particle on another). The given particle set moves through elemental volumes of length $\Delta x$, as one moves left to right from the motor's head end downstream to and through the motor's exhaust nozzle. As with the gas, the particles are allowed to move out of the nozzle expansion's exit plane, with a transmissive right-side boundary at that point to avoid any artificial reflections of significance in regards to influencing flow activity upstream in the combustion chamber.

As noted above, gaseous mass and the associated energy evolving from the burning surface of the solid spherical reactive particles of varying diameters is accounted for in the gas-phase mass and energy conservation equations. The idealized "pre-heated" inert particle assumption, entering the central core flow at $T_{\mathrm{f}}$, is shown in Equation (11). As outlined in [12], the viscous interaction between the gas and a particle from the $i$-th particle set is represented by the drag force $D_{i}$, and the heat transfer from the core flow to a particle from the $i$-th set is defined by $Q_{i}$. In the case of drag between the gas and a representative spherical particle at a given axial location, one notes that:

$$
D_{i}=\frac{\pi d_{\mathrm{mi}}^{2}}{8} C_{\mathrm{d}} \rho\left(u-u_{\mathrm{pi}}\right)\left|u-u_{\mathrm{pi}}\right|
$$

where $C_{\mathrm{d}}$ is the drag coefficient for a sphere in a steady flow with low flow turbulence (determined as a function of the relative Reynolds number, relative flow Mach number and temperature difference between the particle and the gas). In the case of heat transfer from the core flow to a representative particle at a given axial location, the following applies in the inert particle case (this relation may need to be modified for the reactive particle case, given the presence of a high-temperature flame surrounding a given particle):

$$
Q_{i}=\pi d_{\mathrm{mi}} k \cdot \mathrm{Nu} \cdot\left(T-T_{\mathrm{pi}}\right)
$$

where the Nusselt number $\mathrm{Nu}$ can be found as a function of the Prandtl number and the relative Reynolds number for a sphere of mean diameter $d_{\text {mi. }}$. One will need to solve Equations (9) to (11) for each of $N_{\text {set }}$ particle sets as part of the calculation process, where for the example particle subset family described above, $N_{\text {set }}$ has a value of 10 at quasi-equilibrium. 
Longitudinal acceleration $a_{\ell}$ appears in the gas and particle momentum and energy equations as a body force contribution within a fixed Eulerian reference (fixing of $x=0$ to the motor head end, $x$ positive moving right on the structure, as per Figure 1; acceleration of the local surrounding structure rightward is designated positive $a_{\ell}$ ) and may vary both spatially along the length of the motor and with time. The effects of such factors as turbulence can be included through one or more additional equations that employ the information from the bulk flow properties arising from the solution of the above one-dimensional equations of motion. The principal differential equations themselves can be solved via a higher-order, explicit, finite-volume random-choice method (RCM) approach [12,13]. The RCM solver employs a Riemann solution technique noted for low artificial dispersion with the time of wave activity in tubes, etc. The equations of motion of the gas and particles will be solved over a given time step $\Delta t$ (on the order of $1 \times 10^{-7} \mathrm{~s}$ for the present study, given the motor solution node allocation in the axial direction from the head end to nozzle exit plane), in sequence with additional equations for structural motion and the propellant burning rate, as described below.

Structural vibration can play a significant role in non-steady SRM internal ballistic behaviour, as evidenced by the observed changes in combustion instability symptoms as allied with the changes in the structure surrounding the internal flow (e.g., propellant grain configuration, wall thickness, material properties). The level of sophistication required for modelling the motor structure (propellant, casing, static-test sleeve, nozzle) and applicable boundary conditions (load cell on a static test stand) can vary, depending on the particular application and motor design. Montesano et al. [14] employed a finite-element approach towards the structural modeling of the given motor configuration. In the present study, a cylindrical-grain configuration allows for a simpler approach via the thick wall theory, as reported in [15]. The radial deformation dynamics of the propellant/casing/sleeve are modelled by a series of independent ring elements along the length of the motor. With that representation, the following ordinary differential equation applies for the movement of a radial position $r$ within the assembly:

$$
\frac{d^{2} r}{d t^{2}}+\left(2 \xi_{\mathrm{R}} \omega_{\mathrm{nR}}\right) \frac{d r}{d t}+\omega_{\mathrm{nR}}^{2}\left(r-r_{0}-\psi\right)=0
$$

where $r_{\mathrm{o}}$ is the reference radius under no chamber pressure and $\psi$ is the local instantaneous radial displacement under static loading. Equation (15) may be solved using a backward difference scheme. Allowing for viscoelastic behavior, $\xi_{\mathrm{R}}$ is the radial damping ratio. The fundamental natural radial frequency, $\omega_{\mathrm{nR}}$, of the sleeve/casing/propellant assembly may be determined using a commercial finite element analysis software program, if the theoretical approximation is not considered adequate.

Axial motion along the length of the structure is modelled via beam theory and bounded by the spring/damper load cell at the motor's head end. Viscous damping is applied in both the radial and axial directions. Reference structural properties are assumed for an ammonium-perchlorate/hydroxyl-terminated polybutadiene (AP/HTPB) composite propellant surrounded by an aluminum casing and steel sleeve.

With respect to transient, frequency-dependent burning rate modeling, which allows one to solve for the local $r_{\mathrm{b}}$ value for the burning propellant surface at a given time, a generalized Zeldovich-Novozhilov (Z-N) solid-phase energy conservation approach is used in the present simulation program. It may be represented by the following time-dependent temperature-based relationship [16]: 


$$
r_{\mathrm{b}}^{*}=r_{\mathrm{b}, \mathrm{qs}}-\frac{1}{\left(T_{\mathrm{s}}-T_{i}-\Delta H_{\mathrm{s}} / C_{\mathrm{s}}\right)} \frac{\partial}{\partial t} \int_{-\infty}^{0} \Delta T \mathrm{~d} y
$$

where $r_{\mathrm{b}, \mathrm{qs}}$ is the quasi-steady burning rate (the value for the burning rate as estimated from the steady-state information for a given set of local flow conditions above the propellant surface), $T_{i}$ is the initial propellant temperature (e.g., room or outside air temperature) and, in this context, $\Delta T=T(y, t)-T_{i}$ is the temperature distribution in moving from the burning propellant surface at $y=0$ (and $T=T_{\mathrm{s}}$ ) to that spatial location in the propellant where the temperature reaches $T_{i}$. The net surface heat release term appearing in Equation 16, $\Delta H_{\mathrm{s}}$, is commonly included as an add-on correction to the solid-phase energy contribution in an energy-conservation model involving solid propellants (e.g., see Equation (22) below for erosive burning). On a pragmatic level, adjusting the value of $\Delta H_{\mathrm{s}}$ positively upward (the more exothermic contribution) increases the burning response magnitude of the propellant at a given frequency, and vice versa for a more endothermic contribution, which acts to deaden the response [16].

For the numerical solution of the integral of Equation (16), the transient heat conduction in the solid phase can be solved by an appropriate finite-difference scheme. In Equation (16), $r_{\mathrm{b}} *$ is the nominal (unconstrained) instantaneous burning rate. The actual instantaneous burning rate $r_{b}$ may be found as a function of $r_{\mathrm{b}} *$ through the rate limiting equation provided below [16]:

$$
\frac{d r_{\mathrm{b}}}{d t}=K_{\mathrm{b}}\left(r_{\mathrm{b}}^{*}-r_{\mathrm{b}}\right)
$$

The rate limiting coefficient $K_{\mathrm{b}}$ effectively damps ("slows down") the unconstrained burning rate $r_{\mathrm{b}}$ * to allow for a better comparison to experimental transient response data and to prevent artificial burning-rate divergence ("runaway"). A higher value for $K_{\mathrm{b}}$, moving closer to, but still less than $1 / \Delta t$ (i.e., the inverse of the numerical solution time step), tends to shift the peak combustion response frequency $f_{\mathrm{r}}$ to a higher value. Adjusting the value for $K_{\mathrm{b}}$ and $\Delta H_{\mathrm{s}}$ permits one to better compare a given solid propellant's experimentally observed transient response behaviour, for example as determined from a T-burner, where the " $T$ " shape of the apparatus gives it its name [1,9].

The quasi-steady burning rate appearing in Equation (16) may be ascertained as a function of various parameters; in this study, as a function of local static pressure $p$, core flow velocity $u$ (erosive burning component) and acceleration (combined effect of $a_{n}$ and $a_{\ell}$, the normal and lateral/longitudinal vector components), such that:

$$
r_{\mathrm{b}, \mathrm{qs}}=r_{\mathrm{p}}+r_{\mathrm{u}}+r_{\mathrm{a}}
$$

The pressure-based burning component may be found through de St. Robert's empirical law:

$$
r_{\mathrm{p}}=C p^{n}
$$

The flow-based erosive burning component (negative and positive) is established through the following expression [17]:

$$
r_{\mathrm{b}}=\left.\frac{r_{\mathrm{b}}}{r_{\mathrm{o}}}\right|_{\delta_{\mathrm{r}}} \cdot r_{\mathrm{o}}+r_{\mathrm{e}}
$$


where at lower flow speeds, the negative component resulting from a stretched combustion zone thickness $\left(\delta_{\mathrm{r}}>\delta_{\mathrm{o}}\right)$ may cause an appreciable drop in the base burning rate $r_{\mathrm{o}}$, which, in this study, is predominantly the pressure-dependent burning component (when acceleration is present, $r_{\mathrm{o}}$ would be the sum of $r_{\mathrm{p}}$ and $r_{\mathrm{a}}$ ). The stretching of the flame zone at low speed may be viewed as being the result of a laminar-like sliding process of the local axial flow in the boundary layer acting to extend and curve the path of a representative particle moving up from the burning surface towards the flame front, such that the effective reactive length is increased. From [17], in the low-speed regime, the following expression may be applied, such that the core flow Darcy-Weisbach friction factor $f$ is below the limit value $f_{\text {lim }}$, at which point negative erosive burning is no longer in effect:

$$
\left.\frac{r_{b}}{r_{o}}\right|_{\delta_{\mathrm{r}}}=\cos \left[\tan ^{-1}\left(K_{\delta} \delta_{\mathrm{o}}\left[1-\left(f / f_{1 \mathrm{im}}\right)^{1 / 2}\right] \frac{\rho u_{\infty}}{\rho_{\mathrm{s}} r_{o}}\right)\right] f<f_{\mathrm{lim}}
$$

The parameter $K_{\delta}$ is a shear layer coefficient, whose value is set at $2600 \mathrm{~m}^{-1}$, along with a value for $f_{\text {lim }}$ of $2.5 \times 10^{-4}$, producing a good comparison to experimental data for various propellants and motors [17].

At higher flow speeds, the positive erosive burning component $r_{\mathrm{e}}$, which can be established from a phenomenological convective heat feedback premise [16], should dominate:

$$
r_{\mathrm{e}}=\frac{h\left(T_{\mathrm{f}}-T_{\mathrm{s}}\right)}{\rho_{\mathrm{s}}\left[C_{\mathrm{s}}\left(T_{\mathrm{s}}-T_{i}\right)-\Delta H_{\mathrm{s}}\right]}
$$

For practical modelling purposes, the value for net surface heat release term $\Delta H_{\mathrm{s}}$ as specifically employed in Equation (22) is usually small in comparison to the available experimental quasi-steady erosive burning data [17] and, thus, is commonly set to zero when calculating $r_{\mathrm{e}}$ (as is done in this study). The comparable $\Delta H_{\mathrm{s}}$ term in Equation (16), for transient combustion response, is treated separately and may have a significant positive or negative value to better compare to transient experimental data. One can find the effective convective heat transfer coefficient $h$ of Equation (22) as a function of the zero-transpiration (zero blowing) value $h^{*}$ and overall propellant burning rate $r_{\mathrm{b}}$ [17]:

$$
h=\frac{\rho_{\mathrm{s}} r_{\mathrm{b}} C_{\mathrm{p}}}{\exp \left(\frac{\rho_{\mathrm{s}} r_{\mathrm{b}} C_{\mathrm{p}}}{h^{*}}\right)-1}
$$

In turn, the value for $h^{*}$ may be found as a function of the zero-transpiration Darcy-Weisbach friction factor $f^{*}$, via Reynolds' analogy [17]:

$$
h^{*}=\frac{C_{p} \rho u_{\infty}\left(f^{*}\right)}{\operatorname{Pr}^{2 / 3} 8}
$$

In the realm of fully-developed turbulent flow, Colebrook's [18] semi-empirical expression for $f^{*}$ has proven accurate over a wide range of Reynolds numbers:

$$
\left(f^{*}\right)^{-1 / 2}=-2 \log _{10}\left[\frac{2.51}{\operatorname{Re}_{\mathrm{d}}\left(f^{*}\right)^{1 / 2}}+\frac{\varepsilon / d}{3.7}\right]
$$

Through Equation (25), one can see the correlation of propellant surface roughness height $\varepsilon$ and grain port diameter $d_{\mathrm{p}}$ in influencing the magnitude of flow-dependent erosive burning. With composite 
propellants using ammonium perchlorate crystals, the roughness height can commonly be correlated with the AP crystal size.

The effect of normal acceleration $a_{n}$ on the burning rate, in this study resulting from radial propellant/casing/sleeve vibration, may be determined via [19]:

$$
r_{\mathrm{b}}=\left[\frac{C_{\mathrm{p}}\left(T_{\mathrm{f}}-T_{\mathrm{s}}\right)}{C_{\mathrm{s}}\left(T_{\mathrm{s}}-T_{i}\right)-\Delta H_{\mathrm{s}}}\right] \frac{\left(r_{\mathrm{b}}+G_{\mathrm{a}} / \rho_{\mathrm{s}}\right)}{\exp \left[C_{\mathrm{p}} \delta_{\mathrm{o}}\left(\rho_{\mathrm{s}} r_{\mathrm{b}}+G_{\mathrm{a}}\right) / k\right]-1}
$$

where the compressive effect of normal acceleration and the dissipative effect of steady or oscillatory longitudinal (or lateral, if, say, for a star grain configuration) acceleration $a_{\ell}$ are stipulated through the accelerative mass flux $G_{\mathrm{a}}$ :

$$
G_{\mathrm{a}}=\left(\frac{a_{\mathrm{n}} P}{r_{\mathrm{b}}} \frac{\delta_{\mathrm{o}}}{R T_{\mathrm{f}}} \frac{r_{\mathrm{o}}}{r_{\mathrm{b}}}\right)_{\varphi=0} \cdot \cos ^{2} \varphi_{\mathrm{d}}
$$

Note that the longitudinal/lateral acceleration-based displacement orientation angle $\varphi_{d}$ is greater than the nominal acceleration vector orientation angle ( $\varphi$; at the lower limit, $\varphi$ and $\varphi_{\mathrm{d}}$ are zero when only normal acceleration $a_{\mathrm{n}}$ relative to the burning propellant surface is present) [19]. One should also note that $a_{\mathrm{n}}$ is negative when acting to compress the combustion zone and treated as zero when directed away from the zone. For the above case, the base burning rate $r_{\mathrm{o}}$ is a function of the other flow mechanisms (pressure and core flow).

Past studies by some researchers have allowed for the propellant's burning surface temperature $T_{\mathrm{s}}$ to vary as a function of the propellant's burning rate, while others, explicitly or implicitly, have assumed a mean or constant value $[11,16]$. Based on good comparisons in general to the experimental data for various burning mechanisms and conditions, a constant or mean burning surface temperature $T_{\mathrm{s}}$ was employed or implicitly assumed in elements of the numerical combustion model, for the present investigation.

Finally, one needs to address the nominal rate at which the spherical aluminum particles will diminish in size as they move down the central flow. Following the approach that Yang and Yoon [20] used for modelling the regression rate of aluminum particles, via the so-called $\mathrm{D}^{2}$ law (D referring to particle diameter, this law is also known as the evaporation coefficient approach $[21,22]$ ), one can approximate a spherical aluminum particle's nominal regression rate as a function of its current diameter $d_{\mathrm{m}}$ :

$$
r_{\mathrm{b}, \mathrm{p}}=\frac{k_{\mathrm{r}}}{4 d_{\mathrm{m}}}
$$

where $k_{\mathrm{r}}$ is the particle evaporation coefficient. The evaporation law itself (and the $\mathrm{D}^{2}$ name) arises from the following relation for $k_{\mathrm{r}}$, determined as a function of change in the square of the particle diameter over a time increment $\Delta t$ :

$$
k_{\mathrm{r}}=\frac{d_{\mathrm{m}, 0}^{2}-d_{\mathrm{m}, 1}^{2}}{\Delta t}
$$

Given that, in practice, the exponent $n_{\mathrm{p}}$ acting on the particle diameter in the evaporation law of Equation (29) may, in some instances [22], be somewhat to significantly lower than two, the more general expression for the particle regression rate can be given as: 


$$
r_{\mathrm{b}, \mathrm{p}}=\frac{k_{\mathrm{r}}}{2 n_{\mathrm{p}} \cdot d_{\mathrm{m}}^{n_{\mathrm{p}}-1}}
$$

Figure 2 provides the particle regression rate as a function of its diameter, for the cases where $n_{\mathrm{p}}$ is the nominal reference value of two (following the $\mathrm{D}^{2}$ law), $n_{\mathrm{p}}$ is a bit lower at a value of 1.5 and when $n_{\mathrm{p}}$ is at its lower limit (uniform regression rate when $n_{\mathrm{p}}=1$ ). In practice, one may observe the value of $n_{\mathrm{p}}$ becoming lower as the particle diameter falls below a certain threshold size, in some cases with $n_{\mathrm{p}}$ approaching unity at some point [23]. The conversion of an aluminum particle to an effectively inert aluminum oxide $\left(\mathrm{Al}_{2} \mathrm{O}_{3}\right)$ particle would potentially slow the regression rate down to zero. On the other hand, agglomeration of some molten particles within the propellant may take place near the burning surface, and thus, effectively larger particles, to some degree, may be entering into the central flow [23]. That being said, results for the most part using the nominal evaporation law value of two for $n_{\mathrm{p}}$ will be shown later in this paper, as a point of reference for future comparison. Other particle regression models, such as the semi-empirical model proposed by Beckstead [22,23], may prove more accurate when making direct comparisons to experimental firing data for some motors employing an aluminized propellant. For this study, the nominal aluminum particle regression rate is set as $3 \mathrm{~mm} / \mathrm{s}$ when it is a particle diameter of $30 \mathrm{~m}$, as a point of reference, as reflected by Figure 2.

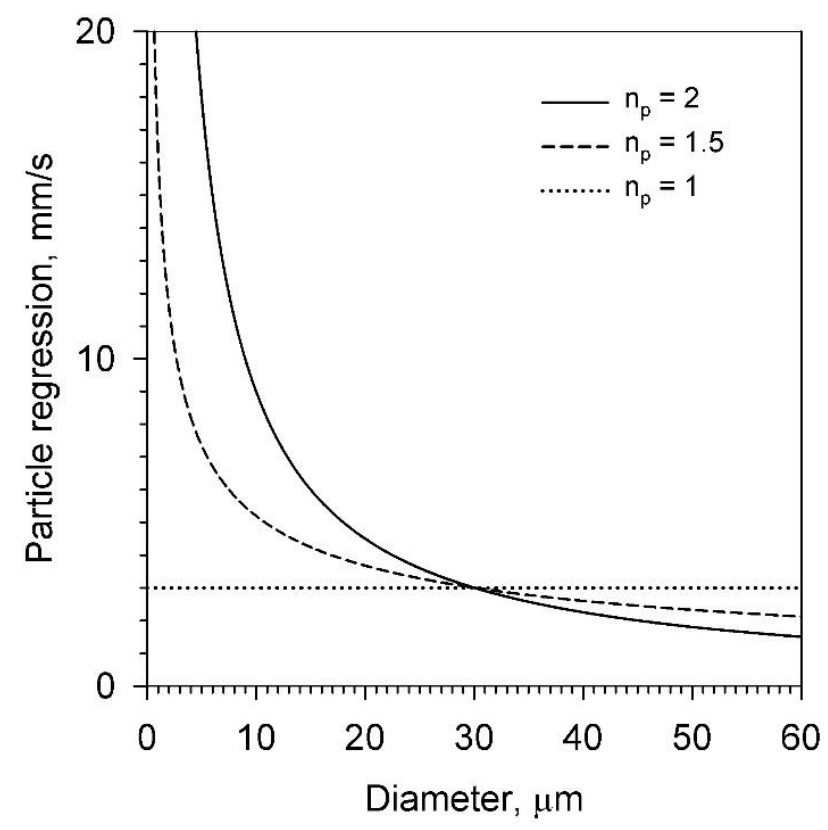

Figure 2. Predicted particle regression rate for $n_{\mathrm{p}}=2\left(\mathrm{D}^{2}\right.$ law, $\left.k_{\mathrm{r}}=3.6 \times 10^{-7} \mathrm{~m}^{2} / \mathrm{s}\right)$, for $n_{\mathrm{p}}=1.5\left(k_{\mathrm{r}}=4.93 \times 10^{-5} \mathrm{~m}^{1.5} / \mathrm{s}\right)$ and for $n_{\mathrm{p}}=1\left(k_{\mathrm{r}}=6.0 \times 10^{-3} \mathrm{~m} / \mathrm{s}\right)$.

\section{Results and Discussion}

The characteristics of the baseline reference motor for this study are listed in Table 1. In the case where the given propellant characteristic was not directly measurable or available, such as mean propellant burning surface temperature $T_{\mathrm{s}}$, assigned values are estimates, for the most part taken from the open or confidential literature, for comparable propellants. Some of the structural properties listed in Table 1, such as damping values, are estimations arising from previous studies involving comparisons to experimental 
vibration data. A nominal value of $2700 \mathrm{~kg} / \mathrm{m}^{3}$ is assigned for the aluminum particles' density ( $\left.\rho_{m}\right)$; one can note that, in practice, liquid (molten) aluminum has a somewhat lower density (around $2400 \mathrm{~kg} / \mathrm{m}^{3}$ ) should the particle's core be liquid, versus solid. In this regard, for some particles transferring from one state to another [24], one can also note that aluminum oxide is significantly heavier, at $3800 \mathrm{~kg} / \mathrm{m}^{3}$. The motor, based in large part on a similar experimental motor [15], is a smaller cylindrical-grain design with an aluminum casing and static-test steel sleeve, with a relatively large length-to-diameter ratio. The motor at the time of pulsing has a moderate port-to-throat area ratio, with a considerable propellant web thickness remaining. The predicted frequency response for the AP/HTPB propellant at three different settings for the net surface heat release value may be viewed in Figure 3 (positive value for $\Delta H_{\mathrm{s}}$, exothermic heat release). The general response is given in terms of the non-dimensional limit magnitude, $M_{\ell}$, defined by:

$$
M_{\ell}=\frac{r_{\mathrm{b}, \text { peak }}-r_{\mathrm{b}, \mathrm{o}}}{r_{\mathrm{b}, \mathrm{qs} \text {,peak }}-r_{\mathrm{b}, \mathrm{o}}}
$$

where the reference burning rate $r_{\mathrm{b}, \mathrm{o}}$ in this case is the motor's approximate mean burn rate at the point of pulsing $(1.27 \mathrm{~cm} / \mathrm{s})$. The propellant's resonant frequency $f_{\mathrm{r}}$ is set via the value of $K_{\mathrm{b}}\left(20,000 \mathrm{~s}^{-1}\right)$ to be on the order of $1 \mathrm{kHz}$ (a value within the range of what might be expected for this type of composite propellant at that base burning rate). This value for $f_{\mathrm{r}}$ is, in fact, relatively close to the fundamental longitudinal acoustic frequency $f_{1 \mathrm{~L}}$ of the combustion chamber, in providing examples later in this paper that are close to the worst-case scenario for susceptibility to axial combustion instability symptoms.

Table 1. Reference motor characteristics.

\begin{tabular}{cc}
\hline Characteristic & Value \\
\hline Propellant grain length, $\ell_{\mathrm{p}}$ & $52 \mathrm{~cm}$ \\
Initial port diameter, $d_{\mathrm{p}, i},{ }$ & $3.6 \mathrm{~cm}$ \\
Nozzle throat diameter, $d_{t}$ & $1.6 \mathrm{~cm}$ \\
Grain/nozzle-convergence length ratio, $\ell_{\mathrm{p}} / \ell_{\mathrm{c}}$ & $16: 1$ \\
Propellant specific heat, $C_{\mathrm{s}}$ & $1500 \mathrm{~J} / \mathrm{kg} \cdot \mathrm{K}$ \\
Propellant density, $\rho_{s}$ & $1730 \mathrm{~kg} / \mathrm{m}^{3}$ \\
Propellant thermal conductivity, $k_{s}$ & $0.4 \mathrm{~W} / \mathrm{m} \cdot \mathrm{K}$ \\
Propellant thermal diffusivity, $\alpha_{\mathrm{s}}$ & $1.54 \times 10^{-7} \mathrm{~m} / / \mathrm{s}$ \\
Propellant flame temperature, $T_{\mathrm{f}}$ & $3000 \mathrm{~K}$ \\
Propellant surface temperature, $T_{\mathrm{s}}$ & $1000 \mathrm{~K}$ \\
Propellant initial temperature, $T_{i}$ & $294 \mathrm{~K}$ \\
Gas specific heat, $C_{\mathrm{p}}$ & $1920 \mathrm{~J} / \mathrm{kg} \cdot \mathrm{K}$ \\
Specific gas constant, $R$ & $320 \mathrm{~J} / \mathrm{kg} \cdot \mathrm{K}$ \\
Gas thermal conductivity, $k$ & $0.2 \mathrm{~W} / \mathrm{m} \cdot \mathrm{K}$ \\
Gas absolute viscosity, $\mu$ & $8.07 \times 10^{-5} \mathrm{~kg} / \mathrm{m} \cdot \mathrm{s}$ \\
Gas specific heat ratio, $\gamma$ & 1.2 \\
De St. Robert exponent, $n$ & 0.35 \\
De St. Robert coefficient, $C$ & $0.05 \mathrm{~cm} / \mathrm{s} \cdot(\mathrm{kPa})^{\mathrm{n}}$ \\
Particle density, $\rho_{m}$ & $2700 \mathrm{~kg} / \mathrm{m}^{3}$ \\
Particle flame temperature, $T_{\mathrm{fp}}$ & $4200 \mathrm{~K}$ \\
Particle solid specific heat, $C_{\mathrm{m}}$ & $900 \mathrm{~J} / \mathrm{kg} \cdot \mathrm{K}$ \\
\hline
\end{tabular}


Table 1. Cont.

\begin{tabular}{cc}
\hline Characteristic & Value \\
\hline Particle mass fraction, $\alpha_{\mathrm{p}}$ & $0 \%$ \\
Propellant elastic modulus, $E_{\mathrm{A}}$ & $45 \mathrm{MPa}$ \\
Propellant Poisson's ratio, $v_{\mathrm{A}}$ & 0.497 \\
Casing inner wall radius, $r_{\mathrm{m}}$ & $3.24 \mathrm{~cm}$ \\
Casing wall thickness, $h_{\mathrm{B}}$ & $0.127 \mathrm{~cm}$ \\
Casing material density, $\rho_{\mathrm{B}}$ & $2700 \mathrm{~kg} / \mathrm{m}^{3}$ \\
Casing elastic modulus, $E_{\mathrm{B}}$ & $80 \mathrm{GPa}$ \\
Casing material Poisson's ratio, $v_{\mathrm{B}}$ & 0.33 \\
Sleeve wall thickness, $h_{\mathrm{C}}$ & $0.47 \mathrm{~cm}$ \\
Sleeve material density, $\rho_{\mathrm{C}}$ & $7850 \mathrm{~kg} / \mathrm{m}^{3}$ \\
Sleeve elastic modulus, $E_{\mathrm{C}}$ & $200 \mathrm{GPa}$ \\
Sleeve material Poisson's ratio, $v_{\mathrm{C}}$ & 0.30 \\
Casing/propellant radial damping ratio, $\xi_{R}$ & 0.35 \\
Casing/propellant axial damping ratio, $\xi_{L}$ & 0.10 \\
\hline
\end{tabular}

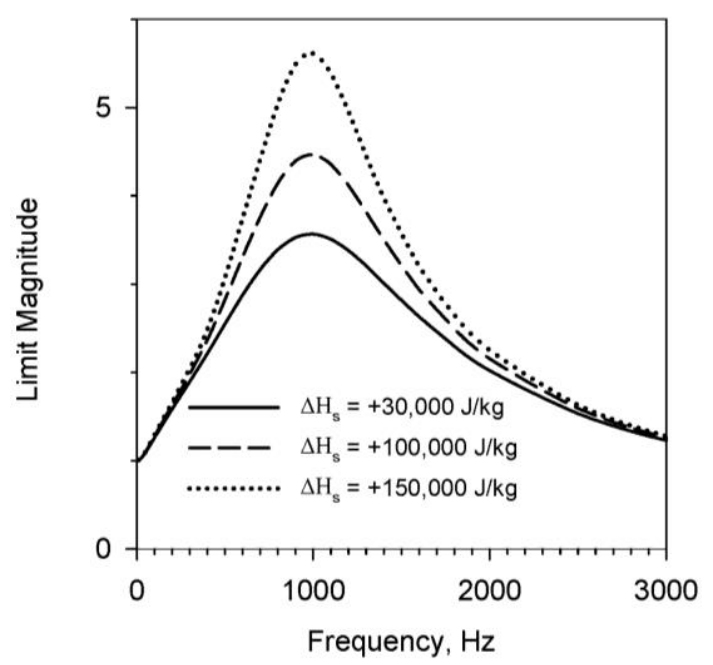

Figure 3. Frequency response of the reference propellant $\left(K_{\mathrm{b}}=20,000 \mathrm{~s}^{-1}\right.$; differing values for $\Delta H_{\mathrm{s}} ; r_{\mathrm{b}, \mathrm{o}}=1.27 \mathrm{~cm} / \mathrm{s}$ ) in terms of the non-dimensional limit magnitude.

An initial pulsed-firing simulation run was completed as the starting reference for this study, in which no particles are present or no other suppression technique is applied. In Figure 4 for head-end pressure $p_{\mathrm{c}}$ as a function of time, one can see that, at some point, the principal compression wave reaches its quasi-equilibrium strength from an initial disturbance pressure $\Delta p_{\mathrm{d}}$ of $2 \mathrm{~atm}$, the sustained compression wave front arriving about every $1 \mathrm{~ms}$, oscillating at the fundamental frequency $f_{1 \mathrm{~L}}$ of $1 \mathrm{kHz}$. The base pressure is not appreciably elevated over the nominal operating chamber pressure. The effect of normal acceleration on the burning process has been nullified for this simulation (in order to isolate the frequency-dependent $\mathrm{Z}-\mathrm{N}$ combustion response as the predominant instability symptom driver), and this is certainly a factor in reducing the development of a dc shift (later results, with acceleration effects on burning included, will further illustrate this point). One can note that the limit pressure wave magnitude ( $\Delta p_{\mathrm{w}}$, peak-to-trough; 
here, $1.42 \mathrm{MPa}$ at the reference time of $0.26 \mathrm{~s}$ ) is decreasing gradually with time after first reaching its quasi-equilibrium level, as the cylindrical grain burns back and the base pressure rises.

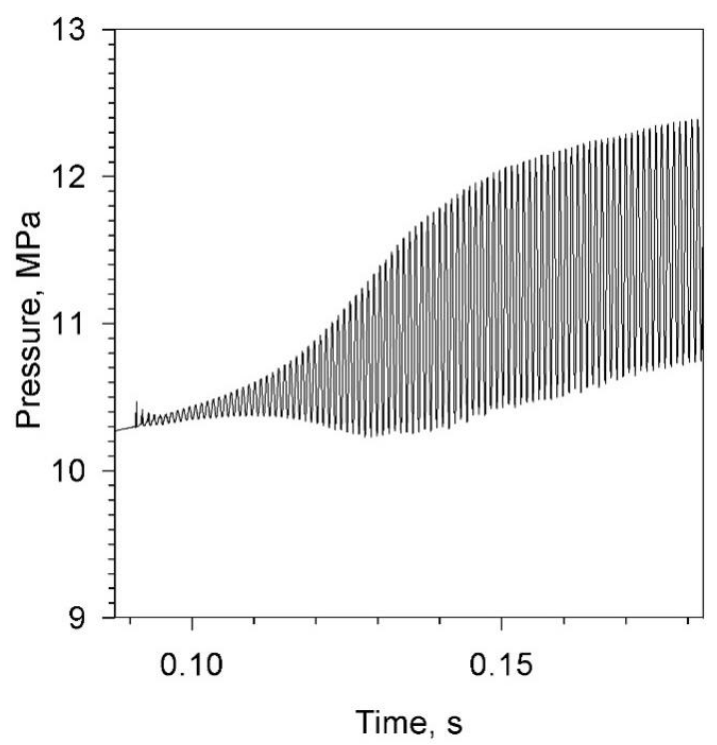

Figure 4. Predicted head-end pressure-time profile, reference motor $\left(K_{\mathrm{b}}=20,000 \mathrm{~s}^{-1}\right.$, $\left.\Delta H_{\mathrm{s}}=150,000 \mathrm{~J} / \mathrm{kg} ; \Delta p_{\mathrm{d}}=2 \mathrm{~atm}\right)$, no particles $\left(\alpha_{\mathrm{p}}=0 \%\right)$, acceleration nullified.

One can refer to Figure 5 for the pressure-time profile for the same motor, but now with $10 \%$ particle loading (by mass) of reactive spherical aluminum particles having a starting diameter of $30 \mu \mathrm{m}$. The spherical particles regress in size at a rate governed by the $\mathrm{D}^{2}$ law of Equation (28), as they enter and move downstream in the internal core flow. The value for the evaporation coefficient $k_{\mathrm{r}}$ is $3.6 \times 10^{-7} \mathrm{~m}^{2} / \mathrm{s}$, as estimated from the results reported in [20], giving a regression rate of $3 \mathrm{~mm} / \mathrm{s}$ when at a diameter of $30 \mathrm{~m}$. Observing the results of Figure 4, the suppression of axial wave development after an initial 2-atm pulse is moderately effective (the limit magnitude of the sustained pressure wave, at $0.26 \mathrm{~s}$, is about $0.75 \mathrm{MPa}\left(\Delta p_{\mathrm{w}}\right)$, as compared to $1.42 \mathrm{MPa}$ for the $0 \%$ loading case noted earlier $\left(\Delta p_{\mathrm{w}, \text { peak }}\right)$, giving a non-dimensional attenuation $M_{\mathrm{a}}$, defined by:

$$
M_{\mathrm{a}}=\frac{\Delta p_{\mathrm{w}, \text { peak }}-\Delta p_{W}}{\Delta p_{\mathrm{w}, \text { peak }}}
$$

a value of 0.47 , noting that a value of unity is a complete suppression. The particle size distribution before the introduction of the initial pressure pulse disturbance is provided in Figure 6. As indicated by the graph, the particles are grouped into 1.5 -m increments $(30,28.5,27, \ldots, 1.5)$ in the numerical model's calculations, hence using 20 particle subsets. In the inert case, one would have around 140,000 particles in a given cell, while here, one notes that there are around 70,000 particles per cell, or a loss of some 70,000 particles per cell due to regression (i.e., about half of the ideal total). One can note that the best case for suppression by an inert particle is from diameters from around 10 to $20 \mathrm{~m}$, to give an $M_{a}$ of around 0.97 at a $5 \%$ loading [7]. The choice of $30 \mathrm{~m}$ for the starting reactive particle diameter was made in light of this, given the regression in size that will be experienced by each particle while moving through the active system. 


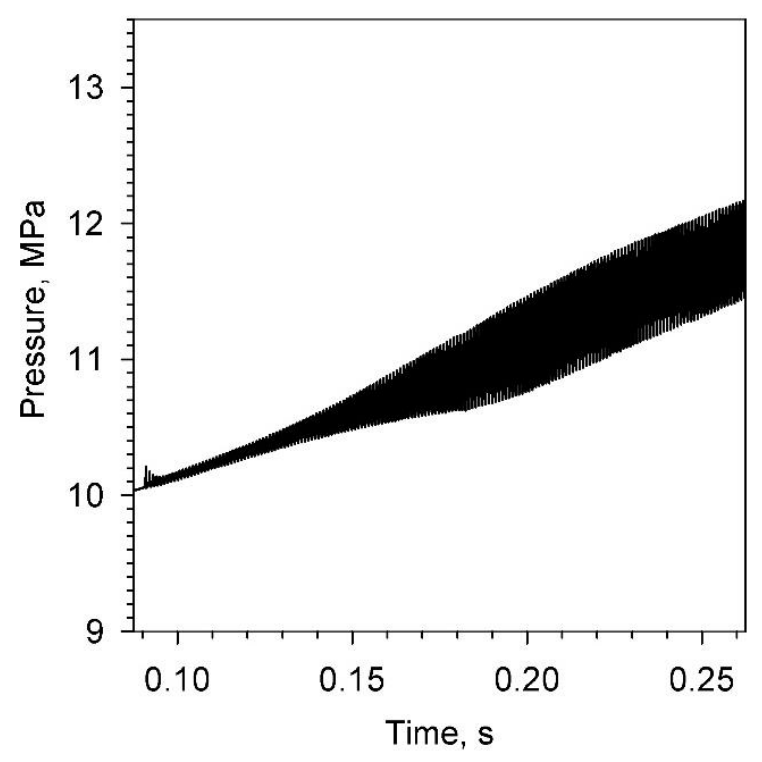

Figure 5. Predicted head-end pressure-time profile, reference motor $\left(K_{\mathrm{b}}=20,000 \mathrm{~s}^{-1}\right.$, $\left.\Delta H_{\mathrm{s}}=150,000 \mathrm{~J} / \mathrm{kg}, \alpha_{\mathrm{p}}=10 \%, d_{\mathrm{m}, \mathrm{o}}=30 \mu \mathrm{m} ; \Delta p_{\mathrm{d}}=2 \mathrm{~atm}\right)$, single regressing particle set (D law, $k_{\mathrm{r}}=3.6 \times 10^{-7} \mathrm{~m}^{2} / \mathrm{s}$ ), acceleration nullified.

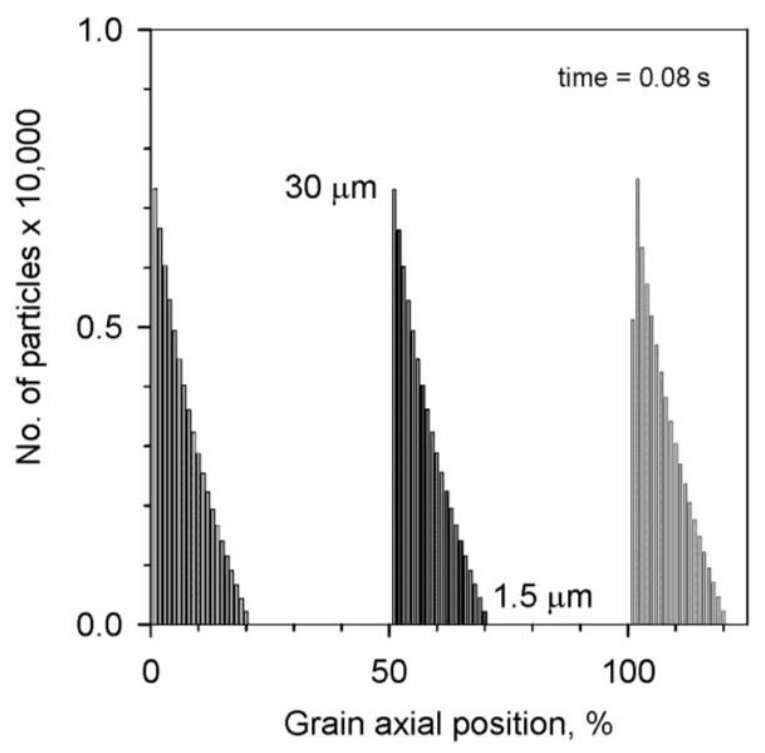

Figure 6. For the simulated firing of Figure 5, the particle size distribution in the element, at different positions along the propellant grain, before the introduction of the initial pressure pulse disturbance.

Figure 7 illustrates the pressure-time profile for the same motor, but now with $20 \%$ particle loading (by mass) of a single set of spherical aluminum particles having a 30- $\mu \mathrm{m}$ diameter initially, with the spherical particles regressing in size at a rate governed by the $\mathrm{D}^{2}$ law noted above. Suppression of axial wave development after an initial 2-atm pulse is very effective (the limit magnitude of the sustained pressure wave, at the reference time of $0.26 \mathrm{~s}$, is about $0.012 \mathrm{MPa}$, as compared to $1.42 \mathrm{MPa}$ for the $0 \%$ loading case noted earlier, giving a non-dimensional attenuation $M_{\mathrm{a}}$ value of 0.99 ). The particle size distribution before the introduction of the initial pressure pulse disturbance is provided in Figure 8 . 


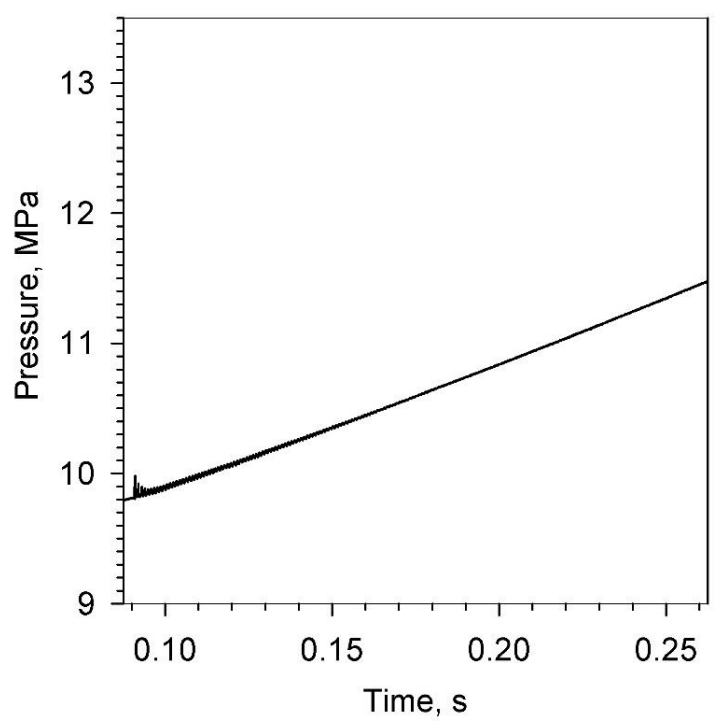

Figure 7. Predicted head-end pressure-time profile, reference motor $\left(K_{\mathrm{b}}=20,000 \mathrm{~s}^{-1}\right.$, $\left.\Delta H_{\mathrm{s}}=150,000 \mathrm{~J} / \mathrm{kg}, \alpha_{\mathrm{p}}=20 \%, d_{\mathrm{m}, \mathrm{o}}=30 \mu \mathrm{m} ; \Delta p_{\mathrm{d}}=2 \mathrm{~atm}\right)$, single regressing particle set (D law, $k_{\mathrm{r}}=3.6 \times 10^{-7} \mathrm{~m}^{2} / \mathrm{s}$ ), acceleration nullified.

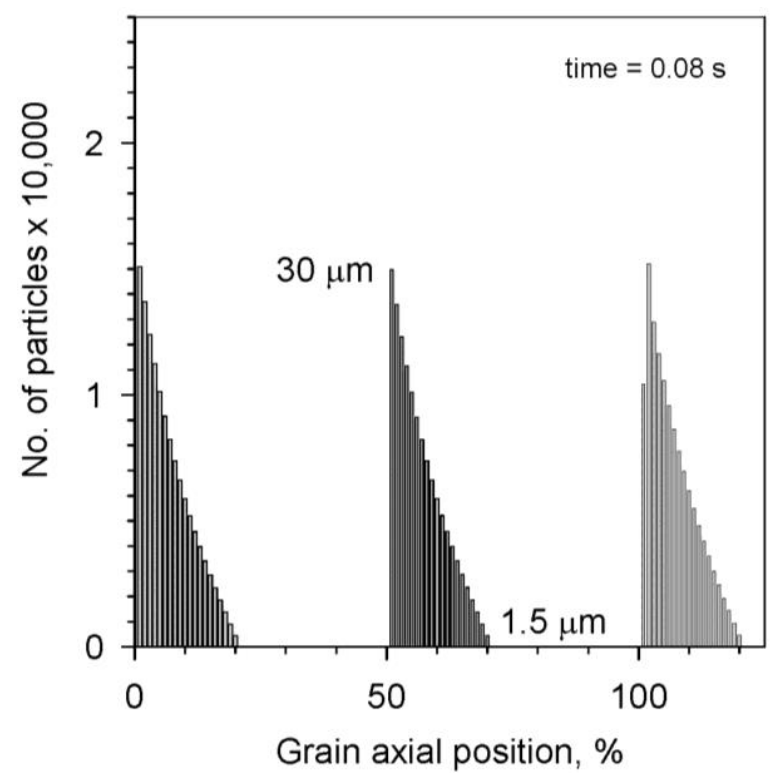

Figure 8. For the simulated firing of Figure 7, the particle size distribution in the element, at different positions along the propellant grain, before the introduction of the initial pressure pulse disturbance.

At this juncture, the influence of normal acceleration on the burning process will be considered. Referring to Figure 9, allowing for the effect of vibration-induced acceleration on combustion in addition to the transient combustion response contribution, one has a very active motor in the absence of particles in the flow, with a large limit magnitude (around $10.2 \mathrm{MPa}$ at $0.26 \mathrm{~s}$ ) for the now shock-fronted axial pressure wave moving back and forth within the chamber, and a visible dc shift is present. 


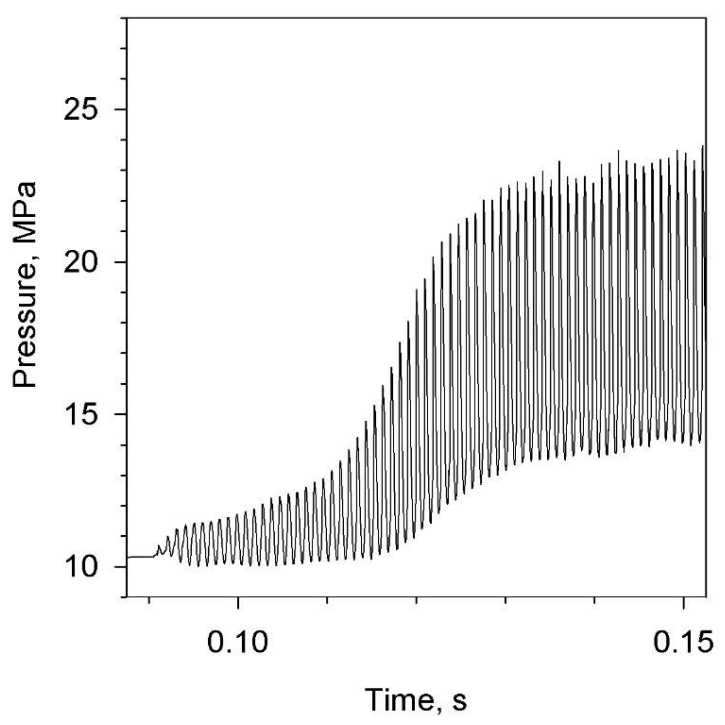

Figure 9. Predicted head-end pressure-time profile, reference motor $\left(K_{\mathrm{b}}=20,000 \mathrm{~s}^{-1}\right.$, $\left.\Delta H_{\mathrm{s}}=150,000 \mathrm{~J} / \mathrm{kg} ; \Delta p_{\mathrm{d}}=2 \mathrm{~atm}\right)$, no particles $\left(\alpha_{\mathrm{p}}=0 \%\right)$, acceleration active.

Employing reactive aluminum particles diminishing in size via the $\mathrm{D}^{2}$ law, one can observe in Figure 10 the predicted pressure-time profile for the same motor, but now with 5\% particle loading (by mass) of reactive spherical aluminum particles having a starting diameter of $50 \mu \mathrm{m}$. The starting particle size is substantially larger than the previous case $(30 \mu \mathrm{m})$, to allow for more effective suppression over the course of the continually diminishing reactive particle's effective lifetime in the combustion chamber (inert particles are comparably effective in the 10- to 35- $\mu \mathrm{m}$ size range [7], albeit at a lower loading percentage). The limit magnitude of the sustained axial pressure wave, at $0.26 \mathrm{~s}$, is about $1.11 \mathrm{MPa}$, which corresponds to an $M_{\mathrm{a}}$ value of 0.89 , which is fairly effective. The particle size distribution before the introduction of the initial pressure pulse disturbance is provided in Figure 11. As indicated by the graph, the particles are grouped into $1.67-\mathrm{m}$ increments $(50,48.33,46.67, \ldots, 1.67)$ in the numerical model's calculations, hence using 30 particle subsets.

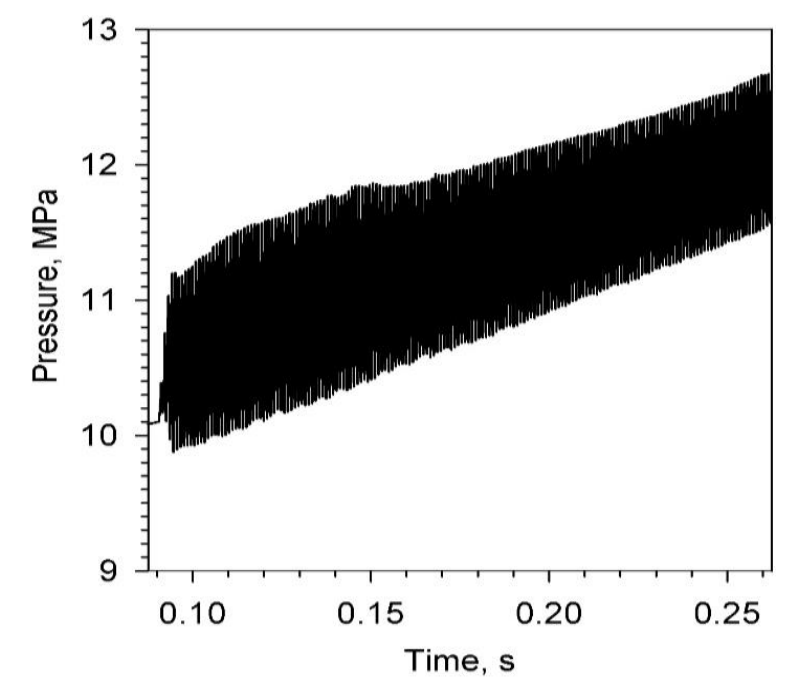

Figure 10. Predicted head-end pressure-time profile, reference motor $\left(K_{\mathrm{b}}=20,000 \mathrm{~s}^{-1}\right.$, $\left.\Delta H_{\mathrm{s}}=150,000 \mathrm{~J} / \mathrm{kg}, \alpha_{\mathrm{p}}=5 \%, d_{\mathrm{m}, \mathrm{o}}=50 \mu \mathrm{m} ; \Delta p_{\mathrm{d}}=2 \mathrm{~atm}\right)$, single regressing particle set (D law, $k_{\mathrm{r}}=3.6 \times 10^{-7} \mathrm{~m}^{2} / \mathrm{s}$ ), acceleration active. 


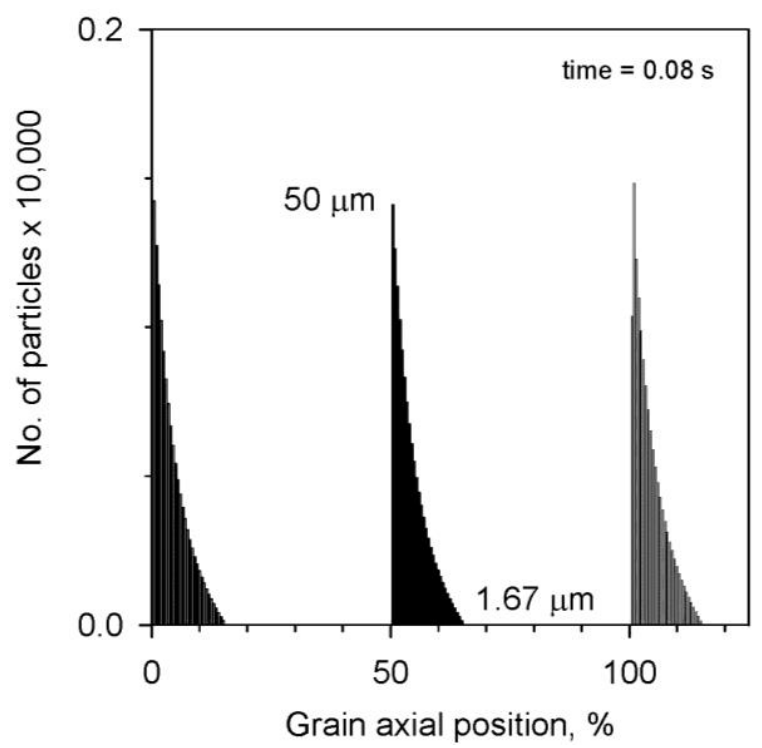

Figure 11. For the simulated firing of Figure 10, the particle size distribution in the element, at different positions along the propellant grain, before the introduction of the initial pressure pulse disturbance.

Figure 12 illustrates the predicted pressure-time profile for a higher loading of $15 \%$ of the $50-\mu \mathrm{m}$ reactive particles. The suppression of axial pressure wave development is considerably improved overall, but in this case, the system appears to be transitioning in a bipolar manner from one quasi-equilibrium wave activity level to another in a cyclic, but progressively decaying fashion, as one moves further in time into the simulated firing. At higher loading percentages, the qualitative pattern persists, albeit with the peak magnitudes of each cycle correspondingly getting smaller relative to that seen at lower particle loading percentages. The particle size distribution before the introduction of the initial pressure pulse disturbance is provided in Figure 13.

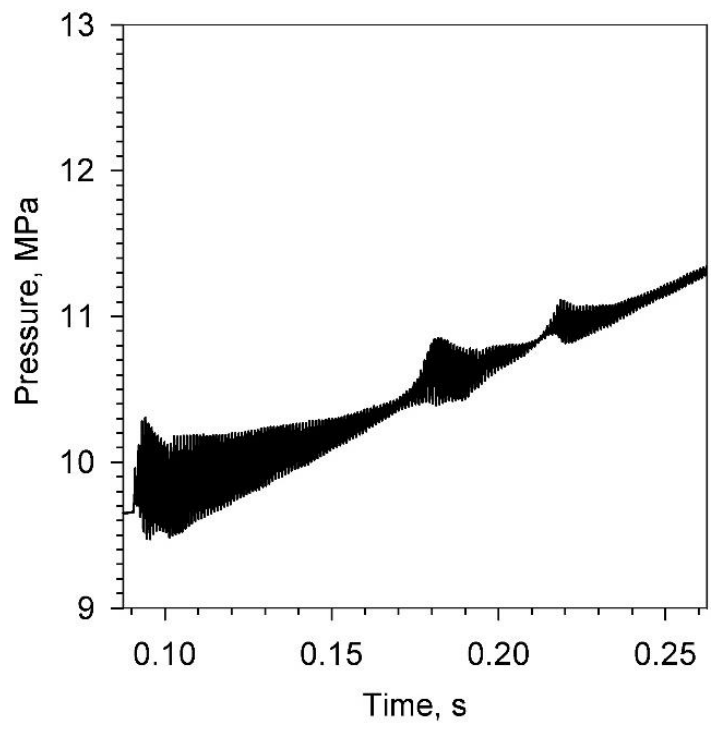

Figure 12. Predicted head-end pressure-time profile, reference motor $\left(K_{\mathrm{b}}=20,000 \mathrm{~s}^{-1}\right.$, $\left.\Delta H_{\mathrm{s}}=150,000 \mathrm{~J} / \mathrm{kg}, \alpha_{\mathrm{p}}=15 \%, d_{\mathrm{m}, \mathrm{o}}=50 \mu \mathrm{m} ; \Delta p_{\mathrm{d}}=2 \mathrm{~atm}\right)$, single regressing particle set (D law, $k_{\mathrm{r}}=3.6 \times 10^{-7} \mathrm{~m}^{2} / \mathrm{s}$ ), acceleration active. 


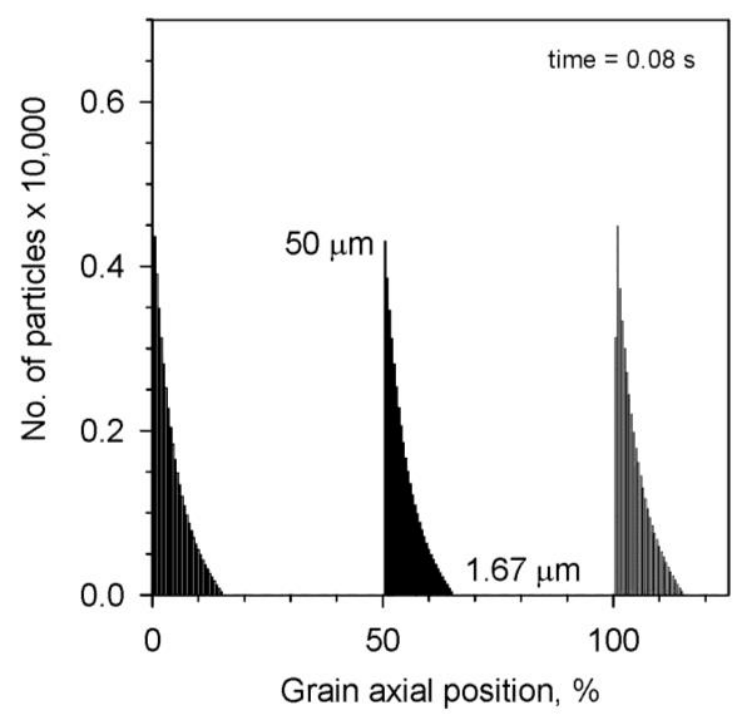

Figure 13. For the simulated firing of Figure 12, the particle size distribution in the element, at different positions along the propellant grain, before the introduction of the initial pressure pulse disturbance.

\section{Conclusions}

The implications of using reactive aluminum particles towards suppressing nonlinear axial combustion instability symptom development have, to some degree, been demonstrated by the example numerical simulation results presented in this study of a small cylindrical-grain solid-propellant rocket motor. The results presented in this paper confirm the importance of particle loading and starting particle size towards mitigating instability symptoms, as these factors work to suppress the influence of the particular propellant's transient frequency-dependent combustion response and normal acceleration-dependent burning sensitivity. Undoubtedly, further work remains to be done, both experimentally and computationally, in establishing a more complete understanding of the various mechanisms involved in driving instability symptoms in these motors. With that understanding, one can, in turn, refine the means by which one can reduce the strength of those undesirable symptoms. In advancing the modelling of aluminum particles for this purpose, in addition to accounting for such factors as agglomeration, one would likely want to consider particle regression models that more comprehensively account for the various factors that are playing a role; a two- or three-dimensional internal ballistic simulation model may be more amenable to such an advancement.

\section{Nomenclature}

$A=$ local core cross-sectional area $\left(\mathrm{m}^{2}\right)$

$a_{\ell}=$ longitudinal (or lateral) acceleration $\left(\mathrm{m} / \mathrm{s}^{2}\right)$

$b=$ non-equilibrium sound speed of a two-phase mixture $(\mathrm{m} / \mathrm{s})$

$C_{\mathrm{m}}=$ solid specific heat of particle $(\mathrm{J} / \mathrm{kg} \cdot \mathrm{K})$

$C_{\mathrm{p}}=$ propellant gas specific heat $(\mathrm{J} / \mathrm{kg} \cdot \mathrm{K})$

$C_{\mathrm{pp}}=$ reactive particle gas specific heat $(\mathrm{J} / \mathrm{kg} \cdot \mathrm{K})$

$C_{\mathrm{S}}=$ propellant specific heat, solid phase $(\mathrm{J} / \mathrm{kg} \cdot \mathrm{K})$ 
$D_{i}=$ drag of gas on a particle from the $i$-th particle set $(\mathrm{N})$

$d=$ local core hydraulic diameter $(\mathrm{m})$

$d_{\mathrm{mi}}=$ mean particle diameter for the $i$-th set (m)

$d_{\mathrm{m}, \mathrm{o}}=$ initial particle diameter $(\mathrm{m})$

$E=$ local total specific energy of gas in the core $(\mathrm{J} / \mathrm{kg})$

$E_{\mathrm{pi}}=$ local total specific energy, $i$-th particle set in the flow $(\mathrm{J} / \mathrm{kg})$

$f=$ frequency $(\mathrm{Hz})$, or Darcy-Weisbach friction factor

$h=$ convective heat transfer coefficient $\left(\mathrm{W} / \mathrm{m}^{2} \cdot \mathrm{K}\right)$

$K_{\mathrm{b}}=$ burning rate damping coefficient $\left(\mathrm{s}^{-1}\right)$

$k=$ gas thermal conductivity $(\mathrm{W} / \mathrm{m} \cdot \mathrm{K})$

$\ell_{\mathrm{p}}=$ propellant grain length $(\mathrm{m})$

$M_{\ell}=$ limit magnitude, cyclic input

$m_{\mathrm{pi}}=$ mass of particle, $i$-th set $(\mathrm{kg})$

$N_{\text {set }}=$ total number of particle sets

$n_{\mathrm{p}}=$ exponent for the particle evaporation law

$p=$ local gas static pressure $(\mathrm{Pa})$

$\Delta p_{\mathrm{d}}=$ magnitude of the initial pressure disturbance $(\mathrm{Pa})$

$Q_{i}=$ heat transfer from gas to a particle in the $i$-th set (W)

$r_{\mathrm{b}}=$ instantaneous burning rate $(\mathrm{m} / \mathrm{s})$

$r_{\mathrm{b}, \mathrm{o}}=$ reference burning rate $(\mathrm{m} / \mathrm{s})$

$r_{\mathrm{b}, \mathrm{pi}}=$ particle regression rate of the $i$-th set $(\mathrm{m} / \mathrm{s})$

$r_{\mathrm{o}}=$ base burning rate $(\mathrm{m} / \mathrm{s})$

$T_{\mathrm{f}}=$ flame temperature, gas phase $(\mathrm{K})$

$T_{\mathrm{fp}}=$ reactive particle flame temperature $(\mathrm{K})$

$T_{i}=$ initial temperature, solid phase $(\mathrm{K})$

$T_{\mathrm{pi}}=$ temperature of the particle from the $i$-th set $(\mathrm{K})$

$T_{\mathrm{s}}=$ burning surface temperature $(\mathrm{K})$

$t=$ time (s)

$u=$ core axial gas velocity $(\mathrm{m} / \mathrm{s})$

$u_{\mathrm{pi}}=$ axial particle velocity of the $i$-th set $(\mathrm{m} / \mathrm{s})$

$v_{\mathrm{f}}=$ nominal flame front velocity $(\mathrm{m} / \mathrm{s})$

$x=$ axial distance from the head end $(\mathrm{m})$

$y=$ distance from the propellant surface into the solid phase $(\mathrm{m})$

$\alpha_{\mathrm{pi}}=$ particle mass fraction of the $i$-th particle set in the overall core flow

$\varepsilon=$ propellant surface roughness $(\mathrm{m})$

$\kappa=$ vibration-based wall dilatation term, $1 / A \cdot \frac{\partial A}{\partial t}\left(\mathrm{~s}^{-1}\right)$

$\rho=$ gas density $\left(\mathrm{kg} / \mathrm{m}^{3}\right)$

$\rho_{\mathrm{m}}=$ solid density of the particle $\left(\mathrm{kg} / \mathrm{m}^{3}\right)$

$\rho_{\mathrm{pi}}=$ particle density in the flow, $i$-th set $\left(\mathrm{kg} / \mathrm{m}^{3}\right)$

$\rho_{\mathrm{s}}=$ solid density of the propellant $\left(\mathrm{kg} / \mathrm{m}^{3}\right)$ 


\section{Conflicts of Interest}

The author declares no conflict of interest.

\section{References}

1. Blomshield, F.S. Historical perspective of combustion instability in motors: Case studies. AIAA Paper No. 2001-3875. In Proceedings of the AIAA/ASME/SAE/ASEE 37th Joint Propulsion Conference, Salt Lake City, UT, USA, 8-11 July 2001.

2. Baum, J.D.; Levine, J.N.; Lovine, R.L. Pulsed instability in rocket motors: A comparison between predictions and experiments. J. Propul. Power 1988, 4, 308-316.

3. Ramohalli, K. Technologies and techniques for instability suppression in motors. In Nonsteady Burning and Combustion Stability of Solid Propellants; Progress in Astronautics \& Aeronautics Series; de Luca, L., Price, E.W., Summerfield, M., Eds.; AIAA Publications: Washington, DC, USA, 1992; Volume 143, pp. 805-848.

4. Price, E.W. Experimental observations of combustion instability. In Fundamentals of Solid-Propellant Combustion; Progress in Astronautics \& Aeronautics Series; Kuo, K.K., Summerfield, M., Eds.; AIAA Publications: Washington, DC, USA, 1984; Volume 90, pp. 733-790.

5. Blomshield, F.S.; Kraeutle, K.J.; Stalnaker, R.A.; Beckstead, M.W.; Stokes, B. Aluminum combustion effects on combustion instability of high burn rate propellants. In Proceedings of the 28th JANNAF Combustion Meeting, CPIA Publication No. 573, 28 October-1 November 1991; Volume III, pp. 419-438.

6. Waesche, R.H.W. Mechanisms and methods of suppression of combustion instability by metallic additives. J. Propul. Power 1999, 15, 919-922.

7. Greatrix, D.R. Inert particles for axial combustion instability suppression in a solid rocket motor. J. Propul. Power 2008, 24, 1347-1354.

8. Greatrix, D.R. Simulation of axial combustion instability development and suppression in solid rocket motors. Int. J. Spray Combust. Dynam. 2009, 1, 143-168.

9. Greatrix, D.R. Scale effects on solid rocket combustion instability behaviour. Energies 2011, 4, 90-107.

10. Greatrix, D.R. Effect of Diminishing particle size on solid rocket combustion instability symptom suppression. AIAA Paper No. 2012-3727. In Proceedings of the AIAA/ASME/SAE/ASEE 48th Joint Propulsion Conference, Atlanta, GA, USA, 29 July-1 August 2012.

11. Greatrix, D.R. Uniform particle regression and solid rocket combustion instability suppression. AIAA Paper No. 2013-4081. In Proceedings of the AIAA/ASME/SAE/ASEE 49th Joint Propulsion Conference, San Jose, CA, USA, 14-17 July 2013.

12. Gottlieb, J.J.; Greatrix, D.R. Numerical study of the effects of longitudinal acceleration on solid rocket motor internal ballistics. J. Fluids Eng. 1992, 114, 404-410.

13. Greatrix, D.R.; Gottlieb, J.J. Higher-order random-choice method for internal ballistic flows. In Proceedings of the 7th Annual Conference of the CFD Society of Canada (CFD 99), Halifax, NS, Canada, 30 May-1 June 1999; pp. 9:15-9:20. 
14. Montesano, J.; Behdinan, K.; Greatrix, D.R.; Fawaz, Z. Internal chamber modeling of a solid rocket motor: Effects of coupled structural and acoustic oscillations on combustion. J. Sound Vib. 2008, $311,20-38$.

15. Greatrix, D.R.; Harris, P.G. Structural vibration considerations for solid rocket internal ballistics modeling. AIAA Paper No. 2000-3804. In Proceedings of the AIAA/ASME/SAE/ASEE 36th Joint Propulsion Conference, Huntsville, AL, USA, 14-17 July 2000.

16. Greatrix, D.R. Transient burning rate model for solid rocket motor internal ballistic simulations. Int. J. Aerosp. Eng. 2008, 2008, 826070:1-826070:10.

17. Greatrix, D.R. Model for prediction of negative and positive erosive burning. Can. Aeronaut. Space J. 2007, 53, 13-21.

18. Streeter, V.L. Fluid Mechanics, 3rd ed.; McGraw-Hill: New York, NY, USA, 1962; pp. 213-222.

19. Greatrix, D.R. Parametric analysis of combined acceleration effects on solid-propellant combustion. Can. Aeronaut. Space J. 1994, 40, 68-73.

20. Yang, H.; Yoon, W. Parametric investigation on the sensitivity of the simplified aluminum combustion modeling. AIAA Paper No. 2010-958. In Proceedings of the AIAA 48th Aerospace Sciences Meeting, Orlando, FL, USA, 4-7 January 2010.

21. Kuo, K.K. Principles of Combustion; John Wiley \& Sons: New York, NY, USA, 1986; pp. 370-379.

22. Beckstead, M.W. A Summary of Aluminum Combustion; NATO Report RTO-EN-023; NATO Research \& Technology Organization: Neuilly-sur-Seine, France, 2004.

23. Maggi, F.; Dossi, S.; de Luca, L.T. Combustion of metal agglomerates in a solid rocket core flow. Acta Astronaut. 2013, 92, 163-171.

24. Najjar, F.M.; Ferry, J.P.; Haselbacher, A.; Balachandar, S. Simulations of solid-propellant rockets: Effects of aluminum droplet size distribution. J. Spacecraft Rockets 2006, 43, 1258-1270.

(C) 2015 by the author; licensee MDPI, Basel, Switzerland. This article is an open access article distributed under the terms and conditions of the Creative Commons Attribution license (http://creativecommons.org/licenses/by/4.0/). 